\title{
Correlation between Sonographic Findings of Maternal Thyroid Gland and Thyroid Function Tests during Pregnancy
}

\author{
Maimoona Rasool', Sarah Maryam', M. Sohail Anjum Noor', Mehreen Fatima', Sultan Ayaz, * \\ Muhammad Numair Younis ${ }^{4}$, Syed Amir Gilani, Raham Bacha', Maria Rasool ${ }^{\text {, }}$, Sadaf Ayesha', \\ Muhammad Yousaf Farooq ${ }^{1}$
}

1 University Institute of Radiological Sciences \& Medical Imaging Technology, Faculty of Allied health Sciences, The University of Lahore, Lahore Pakistan.

2Independent Medical College, Faisalabad, Pakistan.

${ }^{3}$ Department, Nuclear Medicine, Doctors Hospital \& Medical Centre, Lahore, Pakistan.

${ }^{4}$ Directorate of Medical Sciences, Government College University Faisalabad, Pakistan.

${ }^{5}$ Government College University Faisalabad, Pakistan.

Authors' Contributions

1-11 Conception \& Study Design.

1 Data Collection and processing.

4 Data Analysis.

5 Drafting, Critical Review.

\begin{tabular}{l}
\hline Acknowledgement \\
\hline Article info. \\
Received: November 11, 2020 \\
Accepted: December 18, 2020 \\
\hline Funding Source: Nil \\
Conflict of Interest: Nil \\
\hline Cite this article: Rasool M, Maryam S, Noor \\
M.SA, Fatima M, Ayaz S, Younis MN, Gilani \\
SA, Bacha R, Rasool M, Ayesha S, Farooq \\
MY. Correlation between Sonographic \\
Findings of Maternal Thyroid Gland and \\
Thyroid Function Tests during Pregnancy. \\
RADS J Pharm Pharm Sci. 2020; 8(3):147- \\
153. \\
*Address of Correspondence Author: \\
Ayaz libra@hotmail.com
\end{tabular}
ayaz_libra@hotmail.com

\section{A B S T R A C T}

Background: Pregnancy has great influence on maternal thyroid gland. It induces significant physiological as well as hormonal changes that alters the maternal thyroid function. Our goal was to determine this pregnancy associated changes in thyroid gland.

Objective: To correlate the sonographic findings of maternal thyroid gland with thyroid function tests during pregnancy.

Material and methods: 135 pregnant women were recruited in this study, data of TSH, T3 and T4 was obtained and correlated it with the sonographic findings of maternal thyroid gland in each trimester of pregnancy.

Results: In the 135 sampled pregnant women, mean thyroid gland volume was $4.08 \pm 1.19 \mathrm{~cm}^{3}$. The mean levels of T3, T4 and TSH were v3.37 \pm .44 $\mathrm{pmol} / \mathrm{L}, 14.96 \pm 2.49 \mathrm{pmol} / \mathrm{L}$ and $1.21 \pm .92 \mathrm{mIU} / \mathrm{L}$ respectively. A remarkable correlation between thyroid hormones and thyroid volume was observed.

Conclusion: It is concluded that the ultra-sonographic findings is correlated with the thyroid function tests during pregnancy.

Keywords: Pregnancy, Tri-iodothyronine, Tetra-iodothyronine, Thyroid stimulating hormone, TSH, Ultrasonography, Correlation.

\section{INTRODUCTION}

Pregnancy has great influence on maternal thyroid gland. It induces significant physiological as well as hormonal changes that alters the maternal thyroid function. Thyroid gland size is affected by age, gender, iodine supply and TSH [1]. Thyroid gland volume is considered as a function of iodine intake in a population [2]. During gestation, the thyroid gland size increases about $10 \%$ in iodine sufficient countries and 20 to $40 \%$ in iodine deficient countries [3].

During a normal pregnancy, the physiology of thyroid gland is modified perceptibly. These changes occur throughout gestation and it helps the maternal thyroid gland to prepare and cope with the increased 
metabolic demands of gestation. These changes are reversible postpartum [4]. During pregnancy, the thyroid function tests changes mainly due to the effect of two hormones i.e. estrogen and human chorionic gonadotropin (hCG) [5]. The most remarkable changes occur in pregnancy which induces maternal thyroid gland to adapt appropriately. First factor is the adjustment of ratio of bound to free T3 and T4 against the pronounced increase in the circulating concentration of TBGs (thyroxin binding globulin) due to the enhanced production of estrogen. Second factor is the direct stimulation of the thyroid gland by elevated concentrations of human chorionic gonadotropin (hCG), due to the intrinsic thyrotrophic activity of hCG and structural resemblance with TSH. It results in increased T3 and T4 secretion in early gestational phase and plateaus during mid gestation. Both factors occur early in first trimester [6]. Third factor is enhanced enzymatic activity of type III monodeiodinase. It converts T4 to rT3 (reverse T3) which results in increasing the yield of maternal T4 at placental level. This is effective in later gestational phase [7].

All these stimulants of thyroid gland enhance the requirement of iodine which is further aggravated by elevated renal clearance of iodine. Furthermore, amount of iodine is also transported to fetal thyroid gland from maternal circulation, as it becomes functional progressively at the end of the first trimester [8-10].

During pregnancy, the regulation of maternal thyroid gland is very complex and also it varies with each phase of gestation. If the pregnant women are taking the sufficient amount of iodine, then thyroid gland adjusts its hormonal output readily and attains a new state of equilibrium. But it becomes difficult to attain this equilibrium in the situation of low iodine intake [11]. In this condition thyroid adaptations may vary from physiological to pathological, depending on the extent of iodine deficiency [12]. Thyroid hormones play a vital role in early development of fetal brain. Their deficiency may cause impaired development of fetal brain, mental retardation and cretinism [13,14]. The current study was basically designed to determine the alterations in thyroid gland volume and thyroid hormone production in Pakistan, which is considered as moderate to severe iodine deficient country [15-17].

\section{MATERIALS AND METHODS}

This cross sectional study was conducted at the radiology department of Government General Hospital, GMA Faisalabad, Pakistan, from September 2019 to June 2020. Informed consent was obtained by all subjects participated in this study. Institutional review board of Faculty of Allied Health Sciences, University of Lahore, issued the ethical approval reference number: IRB-UOL-FAHS/582/2019, dated: 20, September, 2019. The duration of study was 9 months. The target population was pregnant women. Sampling technique used for the selection of subjects was non-probability convenient sampling. Sample size of 135 was calculated by using the correlation coefficient formula. After approval from institutional review board, the healthy pregnant women in any trimester with single, uncomplicated, intrauterine gestation were recruited in the study. A detailed history was taken from each subject regarding age, Primigravida or multigravida and any thyroid related illness. Those women with diagnosed thyroid gland disorder, or having thyroid surgery, or any metabolic disorder and those on any thyroid medication were excluded.

The maternal thyroid ultrasound was performed in all pregnant women, on ultrasound scanner (GE LOGIC $V 5)$, equipped with a linear transducer of 7.5to 12 $\mathrm{MHz}$. During the ultrasonographic examination, the subjects were in a supine position with their necks slightly extended. The mediolateral dimension of both lobes was measured on the transverse image. The craniocaudal and the anteroposterior dimensions was measured on the longitudinal image. The equation of Brunn et al. was used to estimate volume of each thyroid lobe in $\mathrm{cm}^{3}$ [18]. Volume of lobe $\left(\mathrm{cm}^{3}\right)=$ Mediolateral $(\mathrm{ML})$ dimension $(\mathrm{cm}) \times$ Craniocaudal (CC) dimension $(\mathrm{cm}) \times$ Anteroposterior (AP) dimension $(\mathrm{cm}) \times 0.479$ [Conversion factor].

Thyroid gland volume was acquired by collecting volume of both lobes. Isthmus volume was not included in this calculation. Thyroid gland echotexture, echogenicity and vascularization pattern was also assessed on ultrasound. After taking the informed consent from all subjects, blood sample was collected for the assessment of T3, T4 and TSH. 


\section{RESULTS}

A total of 135 pregnant women meeting selection criteria and volunteered for participating in this study, were examined at the radiology department of Govt. General hospital, GMA Faisalabad. Out of total 135 pregnant women, the frequency of first, second and third trimester was 45 (33.3\%). The mean age of sample population was $30.148 \pm 5.93$ years. The minimum and maximum age in this study was 20 to 42 years. Among 135 pregnant women, 42 (31.1\%) were Primigravida while remaining 93 (68.9\%) were multigravida have had total of 2 to 5 pregnancies. Among multigravida, 42 (31.1\%) women were second gravid, $25(18.5 \%)$ women were third gravid, 18 $(13.3 \%)$ women were fourth gravid and $8(5.9 \%)$ were fifth gravid as shown in figure 1.

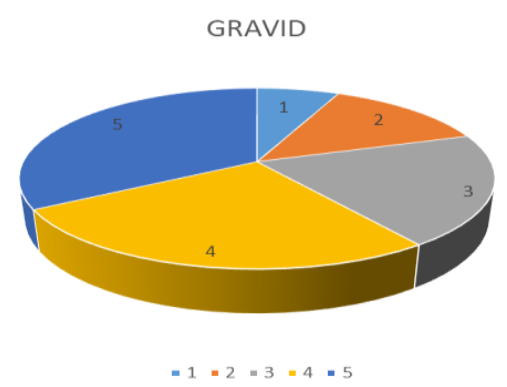

Out of total 135 pregnant women, the mean thyroid gland volume(TGV) was $4.08 \pm 1.19 \mathrm{~cm}^{3}$. The minimum and maximum TGV was 2.02 to $6.77 \mathrm{~cm}^{3}$. The mean TGV in first, second and third trimester was $3.39 \pm 0.91 \mathrm{~cm}^{3}, 4.13 \pm 0.97 \mathrm{~cm}^{3}$ and $4.70 \pm 1.30$ cm3 respectively, as shown in the Table 1 . On ultrasound, the echotexture, echogenicity and vascularization pattern of each thyroid gland was normal. The mean levels of thyroid hormones are shown in the Table 1. The mean TSH level in total sampled population was $1.21 \pm .92 \mathrm{mlU} / \mathrm{L}$. The minimum and maximum level of $\mathrm{TSH}$ was 0.04 to $2.93 \mathrm{mIU} / \mathrm{L}$. The trimester specific mean levels of TSH were $0.16 \pm .06,1.35 \pm .52$ and $2.12 \pm .58 \mathrm{mIU} / \mathrm{L}$ respectively. The total mean of T3 level in sampled population was $3.37 \pm .44 \mathrm{pmol} / \mathrm{L}$. The minimum and maximum level of $\mathrm{T} 3$ was 2.4 to $4.6 \mathrm{pmol} / \mathrm{L}$. The trimester specific means values of T3 were $3.47 \pm .47$, $3.42 \pm .38$ and $3.21 \pm .43 \mathrm{pmol} / \mathrm{L}$ respectively, as shown in Table 1. The total mean level of T4 in our sampled population was $14.96 \pm 2.49 \mathrm{pmol} / \mathrm{L}$. The minimum and maximum value of $\mathrm{T} 4$ was 10.03 to $19.72 \mathrm{pmol} / \mathrm{L}$. The trimester specific mean values of T4 were $16.46 \pm 2.27, \quad 14.8 \pm 2.22$ and $13.64 \pm 2.16 \mathrm{pmol} / \mathrm{L}$ respectively, as shown in Table 1.

Figure 1. Percentage of Primigravida and Multigravida.

Table 1. Total and Trimester Specific Mean of Thyroid Hormones and Thyroid Volume.

\begin{tabular}{|c|c|c|c|c|c|}
\hline \multicolumn{2}{|c|}{ Trimester } & Thyroid Volume & TSH & T3 & T4 \\
\hline \multirow{4}{*}{1.00} & Mean & 3.39920 & .1680 & 3.4733 & 16.4620 \\
\cline { 2 - 6 } & $\mathrm{N}$ & 45 & 45 & 45 & 45 \\
\cline { 2 - 6 } & Std. Deviation & .915349 & .06398 & .47930 & 2.27435 \\
\hline \multirow{4}{*}{2.00} & Mean & 4.13864 & 1.3527 & 3.4267 & 14.8036 \\
\cline { 2 - 6 } & $\mathrm{N}$ & 45 & 45 & 45 & 45 \\
\cline { 2 - 6 } & Std. Deviation & .975881 & .52675 & .38695 & 2.22410 \\
\hline \multirow{3}{*}{3.00} & Mean & 4.70793 & 2.1240 & 3.2133 & 13.6424 \\
\cline { 2 - 6 } & $\mathrm{N}$ & 45 & 45 & 45 & 45 \\
\hline \multirow{3}{*}{ Total } & Std. Deviation & 1.305278 & .58725 & .43724 & 2.16329 \\
\cline { 2 - 6 } & Mean & 4.08193 & 1.2149 & 3.3711 & 14.9693 \\
\cline { 2 - 6 } & Std. Deviation & 1.198534 & .92610 & .44752 & 2.49160 \\
\hline
\end{tabular}

Values of thyroid volume is expressed in $\mathrm{cm} 3, \mathrm{~T} 3 \& \mathrm{~T} 4 \mathrm{in} \mathrm{pmol} / \mathrm{L}$ and TSH in $\mathrm{mIU} / \mathrm{L}$.

Pearson's coefficient of correlation ( $r$ ) between thyroid volume(TV) and TSH in pregnant women is given in the Table 2. An absolute correlation was observed between TSH and thyroid volume in pregnant women. A positive correlation of $r=.444$ was observed between TV and TSH in sampled pregnant population as shown in Figure 2. The value of correlation coefficient between TV and 
TSH during first trimester $r=.353$ was significant with $p$-value $0.017<0.05$. However, a correlation coefficient $r=0.019$ between TV and TSH during second trimester was insignificant with $p$-value
$0.901>0.05$. In third trimester, correlation coefficient between $r=.193$ between TV and TSH was insignificant with $p$-value $0.204>0.05$.

Table 2. Correlation Coefficient (Pearson) Between Thyroid TV, TSH, T3, T4.

\begin{tabular}{|c|c|c|c|c|c|}
\hline & & TV & TSH & T3 & T4 \\
\hline \multirow{3}{*}{ TV } & Pearson Correlation & 1 & $.444^{*}$ & $-.233^{*}$ & $-.182^{*}$ \\
\hline & Sig. (2-tailed) & & .000 & .007 & .035 \\
\hline & $\mathrm{N}$ & 135 & 135 & 135 & 135 \\
\hline \multirow{3}{*}{ TSH } & Pearson Correlation & & 1 & $-.441^{\star *}$ & $.347^{* *}$ \\
\hline & Sig. (2-tailed) & & & .002 & .019 \\
\hline & $\mathrm{N}$ & & 135 & 135 & 135 \\
\hline \multirow{3}{*}{ T3 } & Pearson Correlation & & & 1 & -.235 \\
\hline & Sig. (2-tailed) & & & & .120 \\
\hline & $\mathrm{N}$ & & & 135 & 135 \\
\hline \multirow{3}{*}{ T4 } & Pearson Correlation & & & & 1 \\
\hline & Sig. (2-tailed) & & & & \\
\hline & $\mathrm{N}$ & & & & 135 \\
\hline
\end{tabular}

${ }^{*}$. Correlation is significant at the 0.05 level (2-tailed).

${ }^{* *}$. Correlation is significant at the 0.01 level (2-tailed).

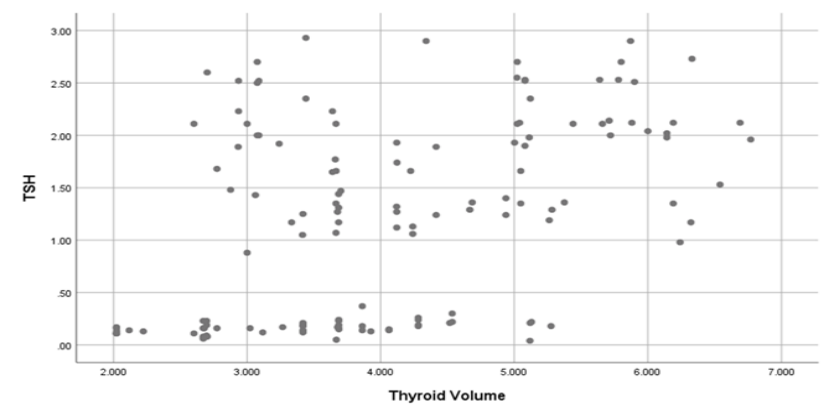

Figure 2. Correlation coefficient (Pearson) between TV and TSH.

A negative correlation was observed between TV and T3 during all trimesters of pregnancy with value of $r=$ -.233 which was significant with $p$-value $0.007<0.05$. as shown in the Figure 3.

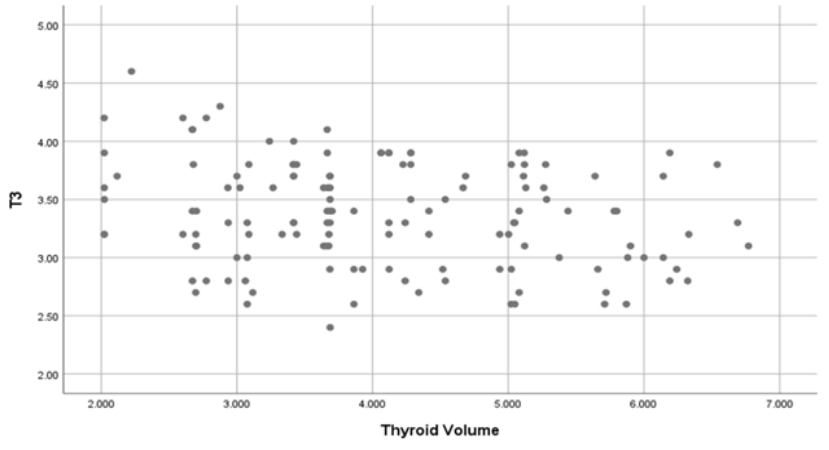

Figure 3. Correlation coefficient (Pearson) between TV and T3.
A negative correlation was also observed between TV and T4 during all trimester of pregnancy with value of $r=-.182$ which is significant with $p$-value $0.035<0.05$, as shown in Figure 4.

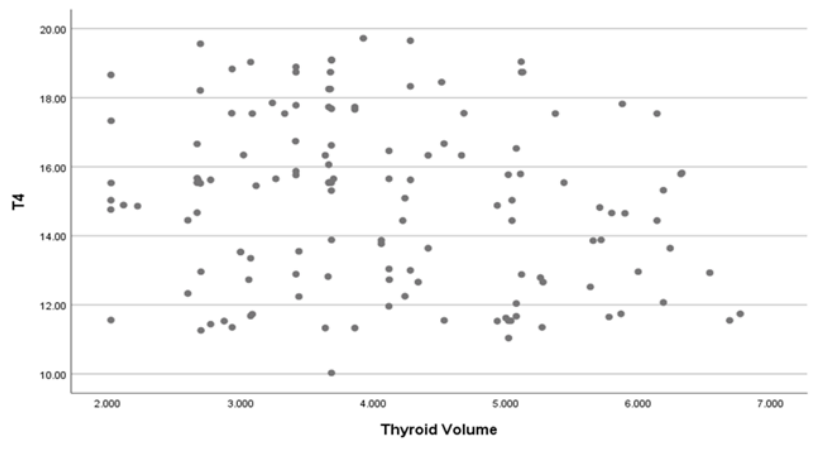

Figure 4. Correlation coefficient (Pearson) between TV and T4

\section{DISCUSSION}

Pregnancy has great impact on maternal thyroid gland. It affects both thyroid gland volume and thyroid functions tests. The present study was planned to report the gestation specific alterations in thyroid gland volume and thyroid function tests. Many countries have established their own reference ranges of thyroid hormones and thyroid gland volume during a normal healthy pregnancy. However, it is a 
known fact that Pakistan is an area of moderate to severe iodine deficiency in the region $[2,8]$. So the population of Pakistan, particularly pregnant women are at higher risk of developing moderate or severe iodine deficiency with adverse maternal as well as fetal outcomes. During pregnancy, maternal thyroid gland begins its supplement functioning immediately after conception by exhibiting elevated T3 and T4 levels, accompanying the raised TBGs concentration, peaking up to seventh weak and stabilizing back to normal levels by sixteenth weak of gestation [19]. It is necessary to determine all key markers of thyroid hormones ( total and free T3 \&T4, TSH, anti thyroid peroxidase antibodies TPO and thyro-globulin antibodies.) for accurate assessment of thyroid functioning during pregnancy. However, due to limited financial resources, the most crucial thyroid markers like T3, T4 and TSH were measured. Free T3 and free $\mathrm{T} 4$ levels were determined rather than total T3 and T4 because TBGs can usually present in slight abnormal concentrations in various physiological conditions e.g pregnancy, drug therapies, proteins abnormalities that affects thyroid hormone binding etc [20]. Consequently, the artefactual alterations in concentrations of TT4 may be common in euthyroid individuals [21]. However, concentrations of free form of thyroid hormones reflected true status of thyroid. For this reason, concentrations of FT3 and FT4 was measured in this study.

In our study, the mean thyroid gland volume was $4.08 \pm 1.19 \mathrm{~cm}^{3}$, which is much smaller than the mean thyroid volume in western countries. The reason for it is the severe deficiency of iodine in Pakistani population, which is highly responsible for smaller thyroid gland volume [22]. However, the reference range of mean thyroid volume in pregnant females is not available in Pakistan, the aim of our study was to establish the reference thyroid volume levels in each trimester of gestation. This study has demonstrated that mean thyroid gland volume increases with each trimester respectively i.e. $3.39 \pm 0.91 \mathrm{~cm}^{3}, 4.13 \pm 0.97$ $\mathrm{cm}^{3}$ and $4.70 \pm 1.30 \mathrm{~cm}^{3}$ in first, second, third trimester respectively as shown in Figure 5 . Our results are consistent with previous study conducted by Okafor Chioma Henrietta in Nigeria [23]. Their results also showed an increase in thyroid gland volume with each trimester respectively.

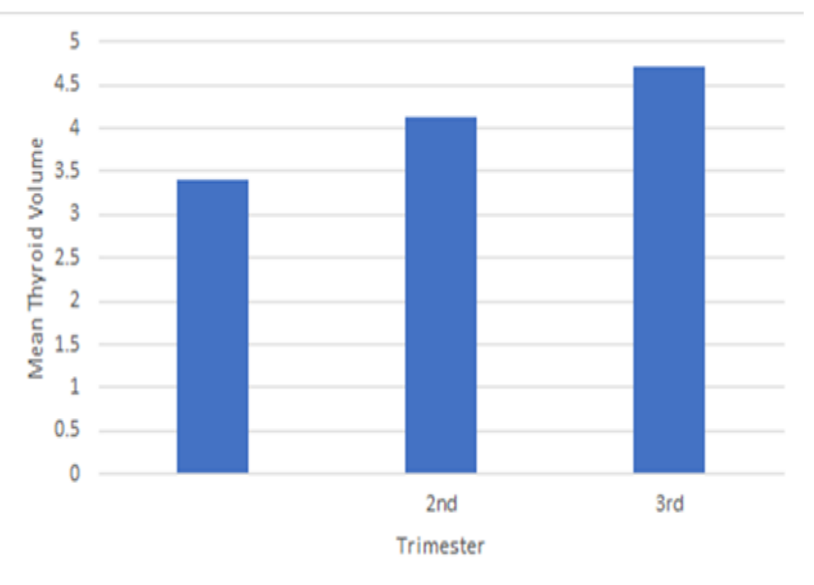

Figure 5. Mean thyroid volume in all trimesters.

In current study, the total mean of T3 level in sampled population was $3.37 \pm .44 \mathrm{pmol} / \mathrm{L}$. A study conducted in urban area of district Rawalpindi, Pakistan in 2018 showed similar outcomes [24]. As compared to the previous study established in Indian population, which showed the trimester specific range of T3 during pregnancy as (1.92-5.86, 3.2-5.73 and 3.3-5.18 $\mathrm{pmol} / \mathrm{L}$ ) [25], the current study showed the variation in mean levels of T3 in first, second and third trimester were $3.47 \pm .47, \quad 3.42 \pm .38$ and $3.21 \pm .43 \mathrm{pmol} / \mathrm{L}$ respectively. However, a longitudinal study established previously in iodine deficient urban area of Pakistan, which showed the similar results to our study. Their results showed that the reference ranges of free T3 in first, second and third trimester were $3.8 \pm 1.1,3.6 \pm 0.9$ and $3.9 \pm 1.0 \mathrm{pmol} / \mathrm{L}$, respectively [8]. So this continuous decrease in the levels of T3 with the progression of each trimester is the result of diversion of available amount of iodine in maternal circulation to thyroid gland of fetus in second phase of gestation, which consequently induces the maternal thyroid gland to prefer the rational synthesis of free T3 instead of free T4, to maintain the state of euthyroidism during this spell of respective iodine deficiency [26].

Our results showed that the total mean of T4 level in our sampled population was $14.96 \pm 2.49 \mathrm{pmol} / \mathrm{L}$. The similar results were observed in a study conducted by Gillani $M$ et al in 2018 in Rawalpindi, Pakistan [24]. Their mean level of free T4 was $14.4 \mathrm{pmol} / \mathrm{L}$. A significant gradual decline in the free T4 levels in this study was observed with progression of gestation. This observation is consistent with preceding cross sectional and longitudinal studies [27-29]. The trimester specific ranges of T4 in present study were $16.46 \pm 2.27, \quad 14.8 \pm 2.22$ and $13.64 \pm 2.16 \mathrm{pmol} / \mathrm{L}$ 
respectively. These results are related to the reference ranges of free T4 observed in the study conducted by Elahi $\mathrm{S}$. et al in an urban area of Pakistan in 2013, which showed the mean levels of T4 in first, second and third trimester were $13.0 \pm 2.8$, $11.5 \pm 1.9$ and $11.3 \pm 1.5$ respectively [8].

\section{CONCLUSIONS}

The reference ranges of mean thyroid gland volume and thyroid function tests T3, T4 and TSH has been established for each trimester of pregnancy in Pakistani population. It is concluded that thyroid gland volume increases with each gestational trimester and there is a significant correlation between maternal thyroid gland volume and thyroid function tests during pregnancy.

\section{RECOMMENDATIONS}

The trimester specific reference intervals for thyroid hormones and thyroid gland volume determined in this study are recommended to be followed in all laboratories in Faisalabad for screening of the thyroid dysfunction in pregnant women.

\section{LIMITATIONS}

Although the present study manifests its importance by establishing the reference interval of maternal thyroid gland volume as well as thyroid hormones for each trimester of pregnancy, but a shortcoming of it includes small sample size and confined to only one hospital of Faisalabad, which may not be the true representative of whole population of Faisalabad. The immediate attention is required to explore these aspects on large scale.

\section{REFERENCES}

1. Attaullah S, Haq BS, Muska M. Thyroid dysfunction in khyber pakhtunkhwa, pakistan. Pakistan journal of medical sciences. 2016 Jan;32(1):111. 10.12669\%2Fpjms.321.8476.

2. Elahi S, Rizvi NB, Nagra SA. lodine deficiency in pregnant women of Lahore. J Pak Med Assoc. 2009 Nov 15;59(11):741-3.

3. Stagnaro-Green A. Abalovich M. Alexander E, Azizi F, Mestman J, Negro R, et al. Guidelines of the American Thyroid Association for the diagnosis and management of thyroid disease during pregnancy and postpartum. Thyroid. 2011 Oct;21(10):1081-25. 10.1089/thy.2011.0087.

4. Sahay RK, Nagesh VS. Hypothyroidism in pregnancy. Indian journal of endocrinology and metabolism. $2012 \quad$ May;16(3):364. 10.4103\%2F2230-8210.95667.

5. Özdikici M. Ultrasonographic Evaluation of Changes in Thyroid Volume In Women During Pregnancy and Lactation. GPH-International Journal of Health Sciences and Nursing $\rightarrow .2018$ Aug 30;1(1):68-72.

6. Glinoer D. The regulation of thyroid function in pregnancy: pathways of endocrine adaptation from physiology to pathology. Endocrine reviews. 1997 Jun 1;18(3):404-33.

7. Glinoer D, NAYER PD, Bourdoux P, Lemone M, Robyn C, STEIRTEGHEM AV, Kinthaert J, Lejeune B. Regulation of maternal thyroid during pregnancy. The Journal of Clinical Endocrinology \& Metabolism. 1990 Aug 1;71(2):276-87. 10.1210/jcem-71-2-276.

8. Elahi S, Hussain Z. A longitudinal study of changes in thyroid related hormones among pregnant women residing in an iodine deficient urban area. International Scholarly Research Notices. 2013;2013.

9. Medici M, Korevaar TI, Visser WE, Visser TJ, Peeters RP. Thyroid function in pregnancy: what is normal?. Clinical chemistry. 2015 May 1;61(5):704-13. 10.1373/clinchem.2014.236646.

10. Stricker RT, Echenard $M$, Eberhart R, Chevailler MC, Perez V, Quinn FA, Stricker RN. Evaluation of maternal thyroid function during pregnancy: the importance of using gestational age-specific reference intervals. European Journal of Endocrinology. 2007 Oct 1;157(4):509-14. 10.1530/EJE-07-0249.

11. Caron P, Hoff M, Bazzi S, Dufor A, Faure G, Ghandour I, Lauzu P, Lucas Y, Maraval D, Mignot $F$, Réssigeac $P$. Urinary iodine excretion during normal pregnancy in healthy women living in the southwest of France: correlation with maternal thyroid parameters. Thyroid. 1997 Oct;7(5):749-54. 10.1089/thy.1997.7.749.

12. Costeira MJ, Oliveira $P$, Ares $S$, Roque $S$, de Escobar GM, Palha JA. Parameters of thyroid function throughout and after pregnancy in an iodine-deficient population. Thyroid. 2010 Sep 1;20(9):995-1001. 10.1089/thy.2009.0356.

13. De Escobar GM, Obregón MJ, Del Rey FE. Role of thyroid hormone during early brain development. European journal of endocrinology. 2004 Nov 1;151(Suppl_3):U25-37. 
14. de Escobar GM, Ares S, Berbel P, Obregón MJ, del Rey FE. The changing role of maternal thyroid hormone in fetal brain development. InSeminars in perinatology 2008 Dec 1 (Vol. 32, No. 6, pp. 380386). WB Saunders. 10.1053/j.semperi.2008.09.002

15. Rasheed H, Elahi S, Syed Z, Rizvi NB. Trend of thyroid dysfunction associated with visible Goiter. Journal of Scientific Research. 2009 Dec;39(2).

16. Akhter P, Orfi SD, Ahmad N. Assessment of iodine levels in the Pakistani diet. Nutrition. 2004 Sep 1;20(9):783-7. 10.1016/j.nut.2004.05.019.

17. Elahi S, Syed Z, Nagra SA. Status of iodinedeficiency disorders as estimated by neonatal cord serum thyrotropin in Lahore, Pakistan. Nutrition research. 2004 Dec 1;24(12):1005-10. 10.1016/j.nutres.2004.07.004.

18. Brunn J, Block U, Ruf G, Bos I, Kunze WP, Scriba PC. Volumetric analysis of thyroid lobes by realtime ultrasound (author's transl). Deutsche Medizinische Wochenschrift (1946). 1981 Oct 1;106(41):1338-40. 10.1055/s-2008-1070506.

19. Jebasingh FK, Salam R, Meetei TL, Singh PT, Singh NN, Prasad L. Reference intervals in evaluation of maternal thyroid function of Manipuri women. Indian Journal of Endocrinology and Metabolism. $2016 \quad$ Mar;20(2):167. 10.4103\%2F2230-8210.176354

20. Garber JR, Cobin RH, Gharib H, Hennessey JV, Klein I, Mechanick JI, Pessah-Pollack R, Singer PA, Woeber for the American Association of Clinical Endocrinologists and American Thyroid Association Taskforce on Hypothyroidism in Adults KA. Clinical practice guidelines for hypothyroidism in adults: cosponsored by the American Association of Clinical Endocrinologists and the American Thyroid Association. Thyroid. 2012 Dec 1;22(12):1200-35.

21. McNeil AR, Stanford PE. Reporting thyroid function tests in pregnancy. The Clinical Biochemist Reviews. 2015 Nov;36(4):109.

22. Kamran M, Raza I, Mukhtair S, Bughio S, Waseem H. Positive Correlation of Thyroid Gland Volume with Isthmus Dimensions and with Anthropometric Parameters through a Cross Sectional Study on Karachi Population. Journal of Advances in Medicine and Medical Research. 2016 Oct 22:1-8. 10.9734/BJMMR/2016/29710.

23. Henrietta OC, Anthony CU, Thomas A. Thyroid volume by ultrasound in asymptomatic gravid and non-gravid controls in a negroid population in Nigeria. Journal of Experimental and Clinical Anatomy. 2015 Jul 1;14(2):116. 10.4103/15962393.177025.

24. Gilani M, Asif N, Akram A, Gilani M, ljaz A, Malik SS. Determination of reference intervals of thyroid markers during pregnancy in Urban area of District Rawalpindi Pakistan. hormones. 2018 Oct 1;4:5.

25. Marwaha RK, Chopra S, Gopalakrishnan S, Sharma B, Kanwar RS, Sastry A, Singh S. Establishment of reference range for thyroid hormones in normal pregnant Indian women. BJOG: An International Journal of Obstetrics \& Gynaecology. $2008 \quad$ Apr;115(5):602-6. 10.1111/j.1471-0528.2008.01673.x.

26. Sánchez-Vega J, del Rey FE, Farinas-Seijas H, de Escobar GM. Inadequate iodine nutrition of pregnant women from Extremadura (Spain). European Journal of Endocrinology. 2008 Oct 1;159(4):439-45. 10.1530/EJE-08-0309.

27. Panesar NS, Li CY, Rogers MS. Reference intervals for thyroid hormones in pregnant Chinese women. Annals of clinical biochemistry. $2001 \mathrm{Jul}$ 1;38(4):329-32. 10.1258\%2F0004563011900830.

28. Zarghami N, Rohbani-Noubar M, Khosrowbeygi A. Thyroid hormones status during pregnancy in normal Iranian women. Indian Journal of Clinical Biochemistry. 2005 Jul 1;20(2):182-5. 10.1007/BF02867424.

29. Dhatt GS, Jayasundaram $R$, Wareth LA, Nagelkerke N, Jayasundaram K, Darwish EA, Lewis A. Thyrotrophin and free thyroxine trimesterspecific reference intervals in a mixed ethnic pregnant population in the United Arab Emirates. Clinica Chimica Acta. 2006 Aug 1;370(1-2):147-51. 10.1016/j.cca.2006.02.008. 